\title{
Vitamin E and Immune System: A Protective Nutrient Against Influenza and COVID-19 in Elderly Humans
}

\author{
Tanveer Jilani ${ }^{1^{*}}$ and Mohammad Perwaiz Iqbal ${ }^{1,2}$ \\ ${ }^{1}$ Department of Biological and Biomedical Sciences, Aga Khan University, Karachi, Pakistan \\ ${ }^{2}$ Department of Life Sciences, University of Management and Technology, Lahore, Pakistan
}

\begin{abstract}
Older adults have relatively weak immune and antioxidant systems and thus, are more vulnerable to viral infections especially respiratory tract infections as compared to younger adults. Recent reports of high mortality rate due to the Coronavirus disease 2019 (COVID-19) in the elderly population are suggestive that perhaps a compromised antioxidant status might be contributing to increased virulence in elderly people. Since vitamin E insufficiency is common in old age, it is conceivable that low vitamin $E$ status could be among the factors causing high mortality in elderly people suffering from influenza and COVID-19 infections. Recent studies have shown an immune-boosting role of supplemental vitamin E along with other antioxidants against respiratory tract viral infections. Therefore, the objective of this review is to examine and discuss the data pertaining to the effects of vitamin $E$ on boosting the immune response against respiratory tract viral infections such as influenza and COVID-19 in elderly individuals.
\end{abstract}

Keywords: Vitamin E supplementation, elderly population, antioxidant status, immune system, respiratory tract infections, influenza, COVID-19.

\section{INTRODUCTION}

Vitamin E was originally discovered by Herbert McLean Evans and Katharine Scott Bishop as an essential dietary nutrient required for normal animal fertility and reproduction [1]. The main dietary sources of vitamin $\mathrm{E}$ include nuts, vegetable seeds and their oils and grains [2].

Table 1 shows the major dietary sources and the average amount of vitamin E per 100 grams of food [3]. Potential health benefits of dietary vitamin $E$ intake in humans are mostly related to the prevention of certain types of cancer, heart disease and other chronic degenerative disorders [4].

Vitamin $E$ is one of the most potent fat-soluble antioxidants located predominantly in the human

Table 1: Major dietary sources and average amount of vitamin E per 100 grams of food [3].

\begin{tabular}{|l|c|}
\hline Dietary Source & $\begin{array}{c}\text { Amount of Vitamin E (mg) } \\
\text { per } \mathbf{1 0 0} \text { gm of Dietary Sources }\end{array}$ \\
\hline Wheat germ oil & 172 \\
\hline Sunflower oil & 46 \\
\hline Cotton seed oil & 44 \\
\hline Safflower seed oil & 42 \\
\hline Almonds & 26 \\
\hline Corn oil & 22 \\
\hline Palm oil & 20 \\
\hline Hazelnuts & 15 \\
\hline Olive oil & 14 \\
\hline Peanut & 05 \\
\hline
\end{tabular}

*Corresponding author: Tanveer Jilani, Department of Biological and Biomedical Sciences, Aga Khan University, Karachi, Pakistan; Email: tanveerjilani@aku.edu

Received: September 28, 2021; Revised: October 25, 2021; Accepted: October 28, 2021 DOI: https://doi.org/10.37184/lnjpc.2707-3521.3.20 cellular membranes, especially in the erythrocyte and muscle membranes. Vitamin $\mathrm{E}$ due to its antioxidant action prevents oxidative stress-induced cellular lipid peroxidation and proteolysis. Normal plasma vitamin E (a-tocopherol) levels in healthy human adults may vary depending upon the consumption of a diet rich or poor in vitamin $\mathrm{E}$ and generally ranges between $5 \mu \mathrm{g} /$ $\mathrm{ml}$ to $15 \mu \mathrm{g} / \mathrm{ml}[5,6]$. However, the prevalence of human vitamin $\mathrm{E}$ deficiency is low, and in elderly subjects, it is often associated with dietary deficiency and chronic gastrointestinal tract fat malabsorption syndromes $[7,8]$. Due to this reason, deficiency of this anti-oxidant vitamin is believed to be more than the younger population. Since the immune system is compromised in elderly people, they become more vulnerable to various viral infections including Coronavirus disease 2019 (COVID-19) infection. The objective of this review is to examine and discuss various lines of evidence regarding the effects of vitamin $E$ on boosting the immune response against respiratory tract viral infections such as influenza and COVID-19 in elderly people.

\section{METHODS}

Research Design and Methods: A systematic literature review was conducted to examine the data pertaining to the effects of vitamin $E$ on boosting the immune response against respiratory tract viral infections such as influenza and COVID-19 in apparently healthy elderly humans.

Search Strategy and Selection Criteria: In this review, the authors explored in detail the scientific works from March 1989 till August 2021 related to the effects of vitamin $\mathrm{E}$ on boosting the immune response against respiratory tract viral infections in elderly individuals. The search strategy adopted was an article title/ 
keywords/abstract-based search using key terms such as 'vitamin E', 'tocopherol', 'elderly people', 'antioxidant status', 'immune system', 'respiratory tract infections, and 'COVID-19'. The literature searches for locating, selecting, extracting, and analyzing the published data were performed using PubMed, Web of Science and Google Scholar. The selected articles and some of their linked references were also reviewed to obtain relevant information. However, the focus was on the effect of vitamin $\mathrm{E}$ on the immune system in elderly people and the mechanism of action in case of any protection against respiratory tracts viral infections such as influenza and COVID-19. The pertinent information including authors, institute, study setting, duration, sample size, target population, age group, objectives and dosage used were extracted from a total of 345 retrieved articles.

\section{Vitamin E and Immune System in Elderly People}

Effect of Vitamin E on Immune System Normal aging process in otherwise healthy elderly individuals is associated with a progressive decline in both cellmediated and humoral immunity. This deterioration in the immune status with increasing age is due to decreased synthesis and release of CD4 +ve and CD8 +ve T lymphocytes, natural antibodies and natural killer (NK) cells, increased destruction of circulating neutrophils by apoptosis, increased production of pro-inflammatory cytokines (e.g. Interleukin-1ß, Interleukin-6, Interleukin-8 and Tumor necrosis factor-alpha) with simultaneous decreased production of anti-inflammatory cytokines (e.g. Interleukin-2 and Interferon-gamma), enhanced production of autoantibodies, reduced immune responses to vaccination and impairment inability to generate immune responses against new/ novel antigens [9-11].

Moreover, some of the earlier studies have suggested that healthy elderly individuals have a relatively compromised antioxidant status [12, 13]. Thus, apparently healthy elderly humans are more predisposed than younger adults to infections, chronic inflammatory diseases, and cancers [14]. Antioxidant vitamins are suggested to modulate and boost up the human immune system [15, 16]. Multiple double-blinded, case-control and placebo-control clinical trials have suggested that supplementation with both natural and synthetic vitamin E given for 1-6 months to apparently healthy elderly human subjects significantly improved their natural and acquired immunity [17-19]. The suggested major immunomodulatory effects of dietary vitamin $E$ in immune cells are depicted in Fig. (1) [17-19].

Vitamin E Protection Against Respiratory Tract Infections. Acute respiratory tract infections are a major cause of morbidity and mortality worldwide. The enhanced respiratory oxidative stress due to viral infections such as influenza has been shown to increase the severity of lung inflammation and altered immune responses, especially in old people and immunosuppressed patients [20].

Some of the antioxidants including vitamin $E$ and its various forms had been previously proposed to play a significant role in protecting lung cells against viral and bacterial infections which often lead to increased intrapulmonary oxidative burden [21, 22].

Some of the earlier clinical trials in the elderly have demonstrated beneficial effects of vitamin $E$ in protecting against acute respiratory infections $[23,24]$.

An earlier experimental animal study conducted on white male albino mice indicated that treatment with alpha-tocopherol significantly reduced the mortality rate and enhanced the mean survival time of these albino mice inoculated with influenza virus [25]. The results of a previous randomized control trial showed that supplementation with 200 I U of vitamin E per day had a protective effect on upper respiratory tract infections, especially the common cold in elderly people [26]. The protective effect of vitamin $\mathrm{E}$ against viral infections is further supported by in vitro experiments in a mouse model in an earlier study by Beck et al. showing that the host nutritional status in terms of antioxidants such as vitamin $\mathrm{E}$ and selenium is critical not only for virulence

\section{Effect of vitamin $\mathbf{E}$ dietary consumption on human immune functions}

$\begin{array}{ccc} & & \\ \text { Neutrophils } & \text { T lymphocytes \& Natural Killer cells } & \text { Monocytes/macrophages } \\ \downarrow & \downarrow & \downarrow \\ \downarrow & \downarrow & \downarrow \text { synthesis of PGE2 through } \\ \uparrow \text { chemotaxis, } & \uparrow \text { membrane integrity, } & \text { inhibition of COX-2 } \\ \uparrow \text { phagocytosis } & \uparrow \text { memory T cells, } \\ & \uparrow \text { synthesis of IFN- } \gamma \text { and IL2, } \\ & \downarrow \text { synthesis of IL4 }\end{array}$

Fig. (1): Immune modulatory mechanisms of vitamin E in human cells (17-19). 
but might also be influencing the genetic make-up of the virus [27].

\section{Vitamin E and COVID-19}

Novel COVID-19 is an acute respiratory viral infection that was initially reported to emerge in December 2019 from Wuhan, China and then within a few months became a worldwide pandemic [28]. Coronavirus infection has been proposed to dysregulate the human immune system by causing pro-inflammatory cytokines (Interleukin-2, I Interleukin-6, Interleukin-7, Tumor necrosis factor-a and Granulocyte-colony stimulating factor) hyper release syndrome, reduction in T and B lymphocytes, decreased activity of NK cells and hyperactivation of cytotoxic T cells $[29,30]$.

Some of the recent studies have illustrated that the severity of COVID-19 is far more in elderly individuals as compared to children and young adults. Poor nutritional status of elderly people (in terms of low levels of essential nutrients and vitamins) in COVID-19 could be contributing to increased virulence and pathology/ mortality in these patients. There is a "cytokine storm" in elderly COVID-19 patients and perhaps due to low levels of some of the vitamins (such as vitamins $D, A, C$, $E)$, these elderly patients are unable to suppress these pro-inflammatory cytokines [31]. Moreover, some human studies have pointed out the potential role of some of the vitamins in the management of COVID-19 patients [32].

It has been suggested that oxidative stress due to excessive production of reactive oxygen species (ROS) might lead to severe local or systemic tissue damage in COVID-19 patients [33]. Some most recent studies have suggested the possible use of dietary and supplemental antioxidant vitamins in the treatment of COVID-19 [34]. Moreover, treatment with some of the antioxidants could play a significant role in the management of excessive inflammation and "cytokine storm" in the elderly COVID-19 patients [35].

\section{Vitamin E Deficiency and Viral Infections}

Vitamin E deficiency had been suggested to increase the virulence and the extent of tissue injury by respiratory viruses in experimental animal studies [36]. Earlier animal studies had suggested the potential use of vitamin $E$ in the treatment of influenza virus infections. It was demonstrated that mice experimentally infected with the influenza virus had developed significantly reduced levels of endogenous vitamin $\mathrm{E}$, and supplementation with vitamin $E$ attenuated the free radicals induced by the virus [37]. An association between decreased vitamin $E$ and $D$ status and infection of bovine coronavirus has been suggested [37].

All these reports support the therapeutic potential of vitamin E against viral infections. However, no clinical trials have been carried out to evaluate the therapeutic potential of vitamin E alone in COVID-19. Some of the recent studies suggest that oxidative stress should be reduced in frail people suffering from COVID-19 infection by increasing their antioxidant defense system [38].

A recent randomized controlled trial is underway to examine the impact of vitamins $A, B, C, D$ and $E$ supplementation on the improvement and mortality rate of COVID-19 patients [39]. The results are likely to provide reasonable evidence regarding the outcomes of this intervention. Moreover, a recent study suggested an immune-boosting role of some of the dietary antioxidants including selenium, vitamin $C$ and vitamin $E$ as well as their specific effect in COVID-19 patients [40].

Older adults (> 65 years) have relatively compromised immune responses as well as antioxidant defense mechanisms, which increases the risk of both infections and chronic inflammatory diseases in them as compared with younger adults [38]. Recent reports of high mortality rates among elderly COVID-19 patients are suggestive that perhaps a compromised antioxidant status might be contributing to severe pathology and increased virulence in elderly people [41]. Since vitamin E insufficiency is most likely to occur in old age, it is conceivable that low vitamin E status and a relatively weak immune system could be among the factors causing high mortality in elderly people suffering from influenza and COVID-19 infections [42]. Some of the recent clinical trials have indicated that supplemental antioxidant vitamins including vitamin $\mathrm{E}$ could be beneficial in reducing the morbidity and mortality of patients infected with respiratory viral infections such as influenza and COVID-19 [43]. However, large clinical trials with larger numbers of subjects are required to unravel this phenomenon.

\section{Immune-boosting in Elderly by Vitamin E}

In a recent chapter in a book on vitamin $E$ in Health and Disease, the role of vitamin $E$ in enhancing immunity in elderly people has been highlighted [44]. Vitamin E was found to increase resistance against viral infections and stimulate the immune response against distinctive antigens. In an interventional study, supplementation with $200 \mathrm{mg}$ of vitamin E per day boosted the immune response in elderly subjects including enhanced $T$ cell proliferation. However, dietary intake of vitamin $\mathrm{E}$ is the best approach to enhance immunity in the elderly, especially in immuno-compromised persons [45]. Supplementation with vitamin $\mathrm{E}$ was found to reverse the age-associated decline in immune responses [45].

\section{Vitamin E Rich Foods}

Although Table 1 lists various vitamin E-rich seed oils and nuts, yet in a balanced diet, different food items need to be consumed to meet the essential nutrient requirements. Some of the other dietary sources of vitamin $\mathrm{E}$ include broccoli, spinach, kiwi fruit, fish and egg yolk [2, 46]. It is suggested that in elderly persons vitamin E-rich diet should preferably be used to meet their Recommended Dietary Allowance (RDA) of $15 \mathrm{mg} /$ day for this vitamin. 


\section{Recommendations/Way Forward}

1. Primary care has a special focus on the elderly population. An adequate anti-oxidant status of elderly people is essential for the prevention of disease in them. Vitamin $E$ along with other antioxidants has great potential. However, the health benefits of vitamin $\mathrm{E}$ supplementation in respiratory viral infections and COVID-19 could be more evident through well-planned, large-scale intervention studies in humans especially those having vitamin $\mathrm{E}$ deficiency/insufficiency.

2. The relationship of vitamin $E$ insufficiency with severity in the pathology of COVID-19 in elderly people needs further investigation.

\section{CONCLUSION}

Vitamin E supplementation is likely to be more beneficial in the elderly population especially those with less than normal levels or compromised antioxidants status. Further research studies are needed to investigate any protective and/or curative role of vitamin $E$ against COVID-19.

\section{ABBREVIATIONS}

Natural killer (NK) cells, Interleukin-2 (IL2), Interleukin-4 (IL4), Interferon-gamma (IFN- $y$ ), Prostaglandin E2 (PGE2), Cyclooxygenase 2 (COX 2) activity.

\section{FUNDING}

Our study involved no funding.

\section{CONFLICT OF INTEREST}

The authors declare no conflict of interest.

\section{ACKNOWLEDGEMENTS}

Declared none.

\section{REFERENCES}

1. Evans HM, Bishop KS. On the existence of a hitherto unrecognized dietary factor essential for reproduction. Science 1922; 56(1458): 650-51.

2. Rizvi S, Raza ST, Ahmed F, Ahmad A, Abbas S, Mahdi F. The role of vitamin $E$ in human health and some diseases. Sult Qaboos Univ Med J 2014; 14(2): E157-E165.

3. Shahidi F, de Camargo AC. Tocopherols and tocotrienols in common and emerging dietary sources: Occurrence, applications, and health benefits. Int J Mol Sci 2016; 17(10): 1745.

4. Aune D, Keum N, Giovannucci E, Fadnes LT, Boffetta P, Greenwood DC, et al. Dietary intake and blood concentrations of antioxidants and the risk of cardiovascular disease, total cancer, and all-cause mortality: a systematic review and dose-response meta-analysis of prospective studies. Am J Clin Nutr 2018; 108(5): 1069-91.

5. Meboobali N, Iqbal MP. A simple micro method for determination of plasma levels of alpha tocopherol (Vitamin E) in Pakistani normal adults. Pak J Pharm Sci 2008; 21(4): 361-5.

6. McBurney MI, Yu EA, Ciappio ED, Bird JK, Eggersdorfer M, Mehta S. Suboptimal serum a-tocopherol concentrations observed among younger adults and those depending exclusively upon food sources. PloS One 2015; 10(8): e0135510.
7. Jilani T, Iqbal MP. Vitamin E deficiency in South Asian population and the therapeutic use of alpha-tocopherol (Vitamin E) for correction of anemia. Pak J Med Sci 2018; 34(6): 1571-6.

8. Traber MG. Vitamin $E$ inadequacy in humans: causes and consequences. Adv Nutr 2014; 5(5): 503-14.

9. Fuentes E, Fuentes M, Alarcon M, Palomo I. Immune system dysfunction in the elderly. Ann. Acad Bras Cienc 2017; 89(1): 28599.

10. Fagnoni FF, Vescovini R, Passeri G, Bolonga G, Pedrazzoni M, Lavagetto G, et al. Shortage of circulating naïve CD8 (+) T cells provides new insights on immunodeficiency in aging. Blood 2000; 95(9): 2860-8.

11. Fortin CF, Larbi A, Dupuis G, Lesur O, Fulop JrT. GM-CSF activates Jak-STAT pathway to rescue polymorphonuclear neutrophils from spontaneous apoptosis in young but not elderly individuals. Biogereontology 2007; 8(2): 173-87.

12. Dato S, De Rango F, Crocco P, Passarino G, Rose G. Antioxidants and quality of aging: Further evidences for a major role of TXNRD1 gene variability on physical performance at old age. Oxid Med Cell Longev 2015; 2015: 926067.

13. Campbell D, Bunker VW, Thomas AJ, Clayton BE. Selenium and vitamin $\mathrm{E}$ status of healthy and institutionalized elderly subjects: analysis of plasma, erythrocytes, and platelets. $\mathrm{Br} \mathrm{J}$ Nutr 1989 62(1): 221-7.

14. McNeil JJ, Nelson MR, Woods RL, Lockery JE, Wolfe R, Reid CM. Effect of Aspirin on all-cause mortality in the healthy elderly. N Engl J Med 2018; 379(16): 1519-28.

15. Lee GY, Han SN. The role of vitamin E in immunity. Nutrients 2018 10(11): 1211

16. Carr AC, Maggni S. Vitamin C and immune function. Nutrients 2017; 9(11): 1211

17. Fuente M De la, Hernanz A, Guayerbas N, Victor VM, Arnalich F. Vitamin $E$ ingestion improves several immune functions in elderly men and women. Free Rad Res 2008; 42(3): 272-80.

18. Wu D, Han SN, Meydani M, Meydani SN. Effect of concomitant consumption of fish oil and vitamin $\mathrm{E}$ on $\mathrm{T}$ cell mediated function in the elderly: a randomized double-blind trial. J Am Coll Nutr 2006; 25(4): 300-06

19. Wu D, Mura C, Beharka AA, Han SN, Paulson KE, Hwag D, et al. Age-associated increase in PGE2 synthesis and COX activity in murine macrophages is reversed by vitamin E. Am J Physiol 1998; 275: C661-C668.

20. Rosano A, Bella A, Gesualdo F, Acampora A, Pezzotti P, Marchetti $S$, et al. Investigating the impact of influenza on excess mortality in all ages in Italy during recent seasons (2013/14-2016/17 seasons) Int J Infect Dis 2019; 88: 127-34.

21. Alvarado A, Arce I. Antioxidants in respiratory diseases. Basic science research and therapeutic alternatives. Clin Res Trials 2016; 3(1): 1-11.

22. Lewis ED, Meydani SN, Wu D. Regulatory role of vitamin E in the immune system and inflammation. IUBMB Life 2019; 71(4): 487 94.

23. Hemila $\mathrm{H}$. Vitamin $\mathrm{E}$ administration may decrease the incidence of pneumonia in elderly males. Clin Interv Aging 2016; 11: 1379-85.

24. Meydani SN, Han SN, Wu D. Vitamin E and immune response in the aged: molecular mechanisms and clinical implications. Immunol Rev 2005; 205: 269-84.

25. Galab ov AS, Mileva M, Simeonova L, Gegova G. Combination activity of neuraminidase inhibitor oseltamivir and a-tocopherol in influenza virus $\mathrm{A}(\mathrm{H} 3 \mathrm{~N} 2)$ infection in mice. Antivir Chem Chemother 2015; 24(3-4): 83-91.

26. Meydani SN, Leka LS, Fine BC, Dallal GE, Keusch GT, Singh MF, et al. Vitamin $\mathrm{E}$ and respiratory tract infections in elderly nursing home residents: a randomized controlled trial. JAMA 2004; 292(7): 828-36.

27. Beck MA, Handy J, Levander OA. Host nutritional status: the neglected virulence factor. Trends Microbiol 2004; 12(9): 417-23. 
28. Sun D, Li H, Lu XX, Xiao H, Ren J, Zhang FR, et al. Clinical features of severe pediatric patients with coronavirus disease 2019 in Wuhan: a single center's observational study. World J Pediatr 2020; 19: 1-9.

29. Giamarellos-Bourboulis EJ, Netea MG, Rovina N, Alkinosglou K, Antoniadou A, Antonakos N. Complex dysregulation in COVID-19 patients with severe respiratory failure. Cell Host Microbe 2020; 27: 992-1000.

30. Li G, Fan Y, Lai Y, Han T, Li Z, Zhou P. Coronavirus infections and immune responses. J Med Virol 2020; 92(4): 424-32.

31. Meftahi GH, Jangravi Z, Sahraei H, Bahari Z. The possible pathophysiological mechanism of cytokine storm in elderly adults with COVID-19 infection: the contribution of "Inflammatory-Aging". Inflamm Res 2020; 1-5

32. Grant WB, Lahore H, McDonnell SL, Baggerly CA, French CB Aliano JL, et al. Evidence that vitamin D supplementation could reduce risk of influenza and COVID-19 infections and death. Nutrients 2020; 12(4): 988.

33. Schonrich G, Raftery MJ, Yvonne Samstag Y. Devilishly radical NETwork in COVID-19: Oxidative stress, neutrophil extracellular traps (NETs), and T cell suppression. Adv Biol Regul 2020; 77 : 100741.

34. Carr AC. A new clinical trial to test high-dose vitamin $C$ in patients with COVID-19. Crit Care 2020; 24: 133.

35. Soto MN, Guarner-Lans V, Soria-Castro E, Pech LM, Perez-Torres I. Is antioxidant therapy a useful complementary measure for COVID-19 treatment? An algorithm for its application. Medicina 2020; 56(8): 386.

36. Beck MA, Kolbeck PC, Rohr LH, Shi Q, Morris VC, Levander $\mathrm{OA}$. Vitamin $\mathrm{E}$ deficiency intensifies the myocardial injury of coxsackievirus B3 infection of mice. J Nutr 1994; 124: 345-58.
37. Mileva M, Galabov AS. Vitamin E and influenza virus infection. Intech Open 2018; 80954: 67-82.

38. Marie-Pierrette Ntyonga-Pono. COVID-19 infection and oxidative stress: an under-explored approach for prevention and treatment?. Pan Afr Med J 2020; 35(2): 12.

39. Beigmohammadi MT, Bitarafan S, Hoseindokht A, Abdollahi A, Amoozadeh L, Abadi MM, Foroumandi M. Impact of vitamins A, B, $C, D$, and $E$ supplementation on improvement and mortality rate in ICU patients with coronavirus-19: a structured summary of a study protocol for a randomized controlled trial. Trials 2020; 21: 614.

40. Shakoor H, Feehan J, Al Dhaheri AS, Ali HI, Platat C, Ismail LC, Apostolopoulos V and Stojanovska L (2021). Immune-boosting role of vitamins D, C, E, zinc, selenium and omega-3 fatty acids: Could they help against COVID-19? Maturitas 2021; 143: 1-9.

41. Gavazzi G, Krause K. Ageing and infection. Lancet Infect Dis 2002; 2(11): 659-66.

42. Meydani SN, Lewis ED, Wu D. Perspective: should vitamin E recommendations for older adults be increased? Adv Nutr 2018; 9(5): 533-43.

43. Alagawany M, Attia YA, Farag MR, Elnesr SS, Nagadi SA, Shafi M, et al. Strategy of boosting the immune system under the COVID-19 pandemic. Front Vet Med 2021; 7: 570748.

44. Kowsalya M, Rajeshkumar MP, Velmurugan T, Sudha KG, Ali $S$. Role of vitamin $E$ in boosting the immunity from neonates to elderly. In: Erkekoglu P, Santos JS, Eds. Vitamin E Health and Disease - Interactions, Diseases and Health Aspects. Intechopen: 2021

45. Gay R, Meydani SN. The effects of vitamin E, vitamin B6 and vitamin B12 on immune functions. Nutr Clin Care 2002; 4(4): 18898.

46. Sharma S, Sheehy T, Kolonel L. Sources of vegetables, fruits and vitamins $A, C$ and $E$ among five ethnic groups: results from a multiethnic cohort study. Eur J Clin Nutr 2014; 68(3): 384-91. 